\title{
Effects of Side-Chain Polyether Additive on Zinc Electrodeposition from Ammoniacal Solution
}

\author{
Shenghai Yang ${ }^{1}$,Hua Liao ${ }^{l}$, Zhimei Xia ${ }^{2,3^{*}}$, Yongming Chen ${ }^{1}$, Duoqiang Zhao ${ }^{1}$,Wenrong Lin $^{1}$ \\ ${ }^{1}$ School of Metallurgy and Environment, Central South University, Changsha 410083, China \\ ${ }^{2}$ School of Metallurgy and Material Engineering, Hunan University of Technology, Zhuzhou, 412007, \\ China \\ ${ }^{3}$ Hunan Key Laboratory of Mineral Materials and Application, Central South University, Changsha \\ 410083, China \\ *E-mail: zhimei_x@163.com
}

doi: $10.20964 / 2020.06 .07$

Received: 5 February 2020 / Accepted: 26 March 2020 / Published: 10 May 2020

\begin{abstract}
A typical side-chain polyether, glycerol polyoxyethylene ether (GPE), was used as a single additive on zinc electrodeposition from ammoniacal solution. The electrochemical effects of GPE additive on zinc electrodeposition were investigated by means of cyclic voltammetry $(\mathrm{CV})$, potentiodynamic polarization tests and chronoamperometry (CA). The morphology of zinc deposits on glassy carbon (GC) surface after zinc electrowinning was observed using SEM (scanning electron microscopy). The results indicated that the nucleation overpotential (NOP) was obviously increased up to $120 \mathrm{mV}$ in addition of $1.5 \mathrm{~g} \mathrm{~L}^{-1}$ GPE in the electrolyte, and the hydrogen evolution reaction was significantly prevented in the presence of additive. The GPE additive has the effect to enhance cathodic polarization. In addition, the zinc electrodeposition process is greatly affected by agitation due to the diffusion control of $\mathrm{Zn}$ ion and the nucleation mechanism of zinc electrodeposition is independent of GPE. The more smooth, compact and fine-grained zinc deposits were obtained with $1.5 \mathrm{~g} \mathrm{~L}^{-1} \mathrm{GPE}$ in the electrolyte.
\end{abstract}

Keywords: Zinc electrodeposition, Side-chain polyether, Ammoniacal solution, Electrochemical characterization, Deposit morphology

\section{$\underline{\text { FULL TEXT }}$}

(C) 2020 The Authors. Published by ESG (www.electrochemsci.org). This article is an open access article distributed under the terms and conditions of the Creative Commons Attribution license (http://creativecommons.org/licenses/by/4.0/). 